\title{
Espacialidades
}

\section{O IMPACTO DA FALTA DE ACESSO ÀS AÇÕES SANITÁRIAS SOBRE A SAÚDE NO AMAZONAS (1907-1912).}

The impact of lack of access to health actions on health in the Amazon (1907-1912).

Thais Teixeira do Nascimento ${ }^{1}$

Artigo recebido em: 19/07/2020.

Artigo aceito em: 17/01/2021.

\section{RESUMO:}

Este texto tem como objetivo refletir acerca do impacto que as diferentes dinâmicas políticas tiveram sobre as ações sanitárias e a saúde durante parte do primeiro período republicano brasileiro (1889-1930). Usamos como fonte documental os relatórios do presidente de Estado aos membros da Assembleia Legislativa do Estado do Amazonas entre 1907 e 1912. Como suporte teórico-metodológico, utilizamos Ujvari (2003) para discutir a evolução do conceito de doença e das chamadas "artes de curar”, e Varga (2007), Peiter (2005) e Albuquerque Júnior (2008) para relacionar as fronteiras sanitárias "dos Amazonas" como um espaço de disputas. Em nossos resultados identificamos que as comissões sanitárias na construção da Estrada de Ferro Madeira-Mamoré não mudaram o quadro sanitário do Estado do Amazonas.

PALAVRAS-CHAVE: Malária; Endemias; Miasmas; Microbiologia.

\section{ABSTRACT:}

This text aims to reflect about the impact that different political dynamics had on sanitary actions and health during the first Brazilian republican period (1889-1930). We use the reports of the President of the State to members of the Legislative Assembly of the State of Amazonas as a documentary source, between the years 1907 and 1912. As theoretical and methodological support, we use Ujvari (2003) to discuss the evolution of the disease concept and the that was called "arts of curing", and Varga (2007), Peiter (2005) and Albuquerque Júnior (2008) to understand the sanitary frontiers "of the Amazonas" as a space for disputes. In our results, we identified that the health commissions in the construction of the Madeira-Mamoré Railway did not change the health situation of the of the State of Amazonas.

KEYWORDS: Malaria; Endemics; Miasmas; Microbiology.

1 Mestranda em História pela Universidade Federal de Goiás (UFG) e graduada em licenciatura em História pela mesma instituição (2019). Faz parte do Grupo de Estudo e Pesquisa História das Práticas da Saúde e da doença, da Universidade Federal do Pará (UFPA). Lattes: http://lattes.cnpq.br/4016554218394394. E-mail: thais.teixeira31@discente.ufg.br 
1. Introdução

O texto tem como objetivo apresentar reflexões acerca do impacto que as diferentes dinâmicas políticas e ações sanitárias tiveram sobre a saúde durante parte do primeiro período republicano (1889-1930). Ao longo do período analisado, verificamos que as práticas médicas e das ações sanitárias se desenvolvem em dois tipos de teorias principais a explicar a forma de contaminação e propagação de doenças: a teoria miasmática ${ }^{2}$ e a teoria microbiana.

Em nosso trabalho, é possível observar a presença de ambas as concepções de contaminação nos relatórios de governadores de Estado do Amazonas. Nesse sentido, além de buscarmos debater a diversidade de ações sanitárias conforme as dinâmicas políticas, observaremos como essas ações médicas/sanitárias eram impactadas pelas concepções e conhecimentos médicos vigentes.

Partindo de uma análise guiada pelo prisma da história social, em que buscamos compreender como a sociedade se orientou a partir das práticas políticas e econômicas empregadas durante a Primeira República. Para realizarmos esse trabalho, nos debruçamos no objetivo de tecer relações entre a constituição política vigente, pautada no saneamento, para o desenvolvimento e integração da chamada Amazônia Ocidental $^{3}$ e os desafios para implantação desse projeto na extensão do Estado do Amazonas. Mas, antes de iniciarmos o debate, é importante frisar que as questões aqui levantadas se referem aos anos de 1907 a 1912.

No ano de 1907, uma portaria do Ministério da Viação, Indústria e Obras Públicas criou a Comissão de Linhas Telegráficas Estratégicas de Mato Grosso ao

\footnotetext{
2 A definição para miasma adotada nesse texto é a mesma exposta por Vital (2010) "Os miasmas eram emanações provindas da decomposição de organismos animais e vegetais. Acreditava-se que essas emanações promoviam o desequilíbrio do organismo humano, prejudicando a saúde e sendo responsável por boa parte das doenças existentes" (VITAL, 2010, p.164).

${ }^{3}$ Composta pelos Estados do Amazonas, Acre, Rondônia e Roraima, a Amazônia Ocidental detém 42,97\% da extensão territorial da Amazônia Legal e comporta aproximadamente 57\% das florestas da região, o que a torna a parte mais preservada da Amazônia, além de ser um estoque de biodiversidade sem igual no planeta. Disponível em <http://www.suframa.gov.br/invest/zonafranca-de-manaus-amazonia-ocidental.cfm> Acesso em 13/05/2020.
} 
Amazonas (CLTEMA) ${ }^{4}$, chefiada pelo então major Cândido Mariano da Silva Rondon. A comissão, formada por um grupo de oficiais e praças do exército brasileiro, percorreu o território que atualmente compreende os estados do Amazonas, Mato Grosso e Rondônia (CASER, 2009, p.13).

A partir da trajetória da comissão, percebemos que a iniciativa de construir linhas telegráficas até o extremo noroeste do país desempenhou grande contribuição para o mapeamento, exploração e o aumento da densidade populacional dos territórios ao noroeste do país. Ao longo dessa iniciativa, no entanto, uma série de questões foram postas, fazendo ser necessário estratégias para continuidade do projeto de integração, que buscava se efetivar nos primeiros anos do Brasil republicano. Entre os principais desafios, estavam a dificuldade de comunicação com os interiores, o saneamento e o combate de doenças.

Para elucidar os problemas que as doenças endêmicas, em especial a malária, causaram a esse empreendimento, utilizaremos como aporte documental as informações sobre o quadro sanitário e a dinâmica política contidas nas mensagens ${ }^{5}$ dos governadores do Estado do Amazonas aos membros da Assembleia Legislativa, entre os anos de 1907 e 1912.

As mensagens são apresentadas em tópicos, correspondendo aos serviços ou comissões que explanam as ações que foram desenvolvidas ao longo do ano. Nesse caso em específico, nos atentamos ao tópico "Higiene e saúde", que devido à ausência de um padrão nas mensagens, também apresentou as nomenclaturas de "Saúde Pública", "Saneamento público" e "Serviço Sanitário".

Nossa análise tem como conceitos principais "doença" e fronteira", estando este último vinculado também ao conceito de "região". Como suporte teóricometodológico, utilizamos Ujvari (2003) para tratar a respeito da evolução do conceito

\footnotetext{
${ }^{4}$ Criada no governo do presidente Afonso Pena (1906-1909), ficou popularmente conhecida como Comissão Rondon.

${ }^{5} \mathrm{O}$ acesso a essa documentação é de livre, podendo ser realizado por qualquer pessoa por meio do site < http://ddsnext.crl.edu/brazil > Acesso em 10/05/2020.
} 


\section{Espacialidades}

de doença e das chamadas "artes de curar" empreendidas ao longo do período republicano.

No que se refere aos conceitos de fronteira e região, ambos se cruzam em nossa tentativa de investigação de uma possível fronteira sanitária existente no Amazonas, e de como essa região não pode ser reduzida apenas a seu aspecto geográfico, mas sim palco de problematizações, sobretudo sobre as disputas que esse espaço é permeado. Para dar suporte a essa discussão, utilizamos como referência Varga (2007), Peiter (2005) e Albuquerque Júnior (2008).

\section{Do progresso ao acesso: os avanços da medicina tropical}

Mesmo com a crença de que a manifestação de doenças e epidemias fossem de providência divina, os povos na antiguidade já apresentavam em sua cultura cuidados com a higiene e o saneamento. Segundo o médico e infectologista Stefan Cunha Ujvari (2003), os etruscos ${ }^{6}$ preocupavam-se com à saúde coletiva.

Os pântanos já eram relacionados, nesse período, ao surgimento de doenças infecciosas, as famosas "febres", por isso, evitava-se construções de cidades próximas a esses locais. Posteriormente, também se iniciaram a drenagem e o aterro de terrenos pantanosos ao redor das cidades.

A malária, doença cujo parasita se reproduz em mosquitos do tipo Anopheles, já era presente ao longo da costa do Mediterrâneo na Antiguidade. Ao se perceber que a doença se manifestava com mais frequência em região pantanosa, e que a drenagem desses cursos de água ocasionava a progressiva diminuição de casos, acreditava-se que o odor desagradável que a região apresentava era responsável pelas febres que atacavam seus habitantes, disso surgiu uma das primeiras nomenclaturas para a doença, malária, o “mau ar” (UJVARI, 2003, p.20).

\footnotetext{
${ }^{6}$ Primeiros habitantes da Península Itálica (UJVARI, 2003, p.21).
} 
A ausência da perspectiva de que a doença pudesse ser transmitida por um mosquito, e não por um local, faz referência a falta de conhecimento sobre o agente responsável pela enfermidade. Antes da descoberta dos micro-organismos, o apossamento de água e o odor fétido que ela propagava foram considerados causa para o surgimento de inúmeras doenças. Dessa crença desenvolveu-se a teoria dos miasmas, ou miasmática.

Essa teoria foi utilizada durante muitos anos para explicar a origem e o contágio por doenças, mas, com a necessidade de se aprimorar o tratamento para essas enfermidades, os médicos continuaram desenvolvendo estudos, com o objetivo de criar métodos mais eficazes para o combate e controle de novas ocorrências de doenças. Nesse quadro histórico se encontram as discussões sobre a malária.

Segundo os historiadores Benchimol e Silva (2008), a malária teria se tornado um problema científico e prático para a medicina entre os anos de 1880 e 1890 . Na década de 1870, a escola alemã de Robert Koch e a francesa de Pauster já haviam se debruçado sobre a elucidação do papel das bactérias como causadoras de doenças infecciosas. Até o final de 1890, já havia sido descoberto os agentes responsáveis pelo antraz, a febre tifoide, lepra, malária, tuberculose, cólera, infecções de pele, difteria, tétano, pneumonia e gonorreia.

Ao analisarmos a historicidade da medicina e das doenças, notamos que os deslocamentos humanos no decorrer da história sempre estiveram associados ao transporte de agentes causadores de doenças, podendo infectar outras pessoas. Durante a colonização na costa brasileira, por exemplo, as doenças infecciosas contribuíram para a drástica diminuição da população indígena. Entre as principais causas para o extermínio desses nativos estavam: a relação violenta que foi estabelecida com eles pelos colonizadores em vários momentos, e por conta dos agentes infecciosos trazidos pelos portugueses.

Em 1850 aconteceu no Rio de Janeiro uma epidemia em consequência da proliferação de mosquitos, em que aproximadamente um terço da população foi contaminada pela febre amarela, que matou cerca de mil pessoas em todos os verões 
da cidade até 1890. Mesmo com a criação da Junta Central de Higiene pelo governo imperial, a quantidade de mortes continuou crescente (UJVARI, 2003).

Apesar dos diversos estudos empreendidos pelo sistema de saúde, não foi possível conter a devastação provocada pela doença, que era fonte de controvérsias entre os médicos e estudiosos (SCHWEICKARDT, 2009). Mas, apesar do exemplo da propagação mais intensa durante o período colonizatório, é importante enfatizar que a transmissão desses agentes ocorre amplamente durante todos os tempos históricos.

No início do período republicano, o crescente número de casos pode ser atribuído à exploração e ocupação nacional dos territórios até então considerados "sertão", tornando assim, ainda mais evidentes os casos de endemias e epidemias?. Em todo o mundo houve aumento de manifestações mais intensas de doenças, no decorrer da segunda metade do século XIX, em decorrência do crescimento industrial, que implicou o deslocamento de enormes contingentes populacionais.

Nesse contexto histórico, a propagação de doenças foi acelerada devido à migração de grandes grupos de pessoas do campo para a cidade, às jornadas de trabalho muito longas, à falta de condições sanitárias no trabalho e as moradias pouco confortáveis e abafadas. O Brasil, mesmo não sendo uma potência industrial, também foi afetado por esse aumento de patologias.

Em fins do século XIX, no Brasil, com o aumento das exportações, as ferrovias multiplicaram. O contingente de imigrantes ampliou-se ainda mais entre os anos de 1890 e 1899. Chegaram cerca de 120 mil imigrantes ao país por ano, mas, mesmo com uma política migratória tão próspera nesse período, as questões sanitárias

\footnotetext{
7 Segundo Ujvari (2003), "endemia" refere-se a uma "doença que existe constantemente em determinado lugar e ataca um número maior ou menor de indivíduos. Por exemplo, a Amazônia é uma região endêmica para a malária", enquanto "epidemia" corresponde a uma "doença que surge rapidamente num lugar e acomete simultaneamente um grande número de pessoas", como a peste bubônica no Brasil.
} 
e o terror pela febre amarela foram palco para a necessidade de uma série de medidas para dar continuidade a esse movimento de imigrações ao país.

O historiador Luiz Antônio de Castro Santos (1985, p.2) aponta que “(...) em 1903, ano em que Rodrigues Alves e Oswaldo Cruz iniciavam a campanha pela erradicação da febre amarela no Rio de Janeiro, o número de imigrantes caiu a 34 mil". Dando continuidade à sua reflexão sobre o obstáculo que as condições das cidades brasileiras causavam para a modernização do país, Santos afirma que a luta pela resolução dessa questão, e assim, a possível continuidade da vinda de imigrantes europeus ao Brasil teriam contribuído para o progresso do movimento de saúde coletiva no país.

A malária foi motivo de atenção para a saúde coletiva brasileira desde o período colonizatório. Com a chegada das embarcações portuguesas e a progressiva ocupação de territórios próximos a regiões pantanosas, rapidamente a quantidade de casos da doença foi se multiplicando. Os criadouros dos mosquitos do gênero Anopheles, vetor da doença, localizam-se em lugares com elevada umidade, calor e água parada ou com pequena correnteza e, devido à predominância dessas características na região Amazônica (PEITER, 2005).

Dentre os inúmeros registros de malária na região Amazônica, utilizaremos como exemplo a construção da Estrada de Ferro Madeira-Mamoré8. O empreendimento foi consolidado no prazo acordado, entre 1907 e 1912 e o impacto da malária sobre os trabalhadores provocou uma série de debates sobre a importância da medicina tropical para o tratamento dessa e de outras doenças durante o período republicano.

\footnotetext{
8 Parte do acordo de Petrópolis (1903), estabelecido entre Bolívia e Brasil pôs fim às disputas da região de divisa entre os dois países, a ferrovia seria utilizada para a vazão do látex boliviano.
} 
3. Um olhar sobre os trabalhadores: o impacto das ações sanitárias sobre a saúde e o trabalho

Ao tratarmos a respeito do avanço da medicina tropical, mais do que estudar como ela se desenvolveu, é importante nos atentarmos à forma com que essas novas descobertas eram levadas e aceitas em diferentes regiões do país. O conceito de "região", empregado nesse texto é fruto das reflexões realizadas por Albuquerque Júnior (2008, p.58). Segundo o autor,

(...) o historiador que se interessa pela região, por qualquer recorte espacial que assim é nomeado, deve estar atento para os afrontamentos políticos, as lutas pelo poder, as estratégias de governo, de comando, os projetos de domínio e de conquista que aí estão investidos, que fizeram parte de sua instalação e demarcação, que estabeleceram as fronteiras e os limites que agora podem reivindicar como sendo naturais, ancestrais, divinos ou legítimos.

As regiões, portanto, não pré-existem aos fatos que as fizeram emergir; as regiões são acontecimentos históricos, são acontecimentos políticos, estratégicos, acontecimentos militares, diplomáticos, são produto de afrontamentos, de disputas, de conflitos, de lutas, de guerras, de vitórias e de derrotas. Falar em região implica em se perguntar por domínio, por dominação, por tomada de posse, por apropriação (...).

A história da construção da ferrovia Madeira-Mamoré nos exige a mesma reflexão elencada por Albuquerque Júnior, na medida em que, junto com a construção de seus trilhos, a região foi sendo montada em seu entorno. Desde o período imperial esse território foi palco de inúmeros conflitos. No que se refere a iniciativa do projeto ferroviário, a disputa entre Bolívia e Brasil pela exploração da seringa e o transporte dos produtos para o interior dos dois países foi motivo para diversos conflitos. A solução desse impasse começou a ser visualizada com a assinatura do Tratado de Petrópolis, em 1903.

Mesmo com a finalização de sua construção em 1912, a ferrovia passou por diversas mudanças de definição territorial, a começar pelas fronteiras que a delimitavam a uma região específica no país. Segundo Ferreira (2005, p.345/346),

No dia 13 de setembro de 1943, pelo Decreto-Lei n 5.812, o Governo Federal criou o Território Federal do Guaporé, com áreas desmembradas dos Estados de Mato Grosso e Amazonas. Em conseqüência, toda a Estrada de Ferro Madeira-Mamoré ficava dentro desse Território (...). 
(...) Em17 de fevereiro de 1956, pela Lei n 2.731, o Território passou a ser denominado Território de Rondônia.

Embora o trecho acima aponte que o local onde se encontra a EFMM pertencia aos estados do Amazonas e do Mato Grosso, nos deteremos apenas a análise das informações contidas nas mensagens enviadas para a Assembleia Legislativa amazonense. Elas apontam como a dinâmica política foi organizada pelos governantes do estado, com o objetivo de resolver, ou apenas contornar, as questões sanitárias que impulsionavam a propagação de doenças que atacavam os trabalhadores da Estrada de Ferro Madeira-Mamoré.

Na mensagem enviada pelo governador do Estado Dr. Antônio Constantino $\operatorname{Nery}^{9}$ (1907, p.23), foi abordado a respeito da constante propagação de doenças para o interior do estado,

Movimentado, como é, o nosso porto, frequentado constantemente por grande numero de vapores profundos de outros Estados da Republica onde grassam, em forma epidêmica, o pathos levantino e a varíola, não conseguiram, felizmente, estas terríveis moléstias irromper nesta capital, graças aos meios de precaução e defesa que têm sido empregados, mantendo-se um serviço permanente de prophylaxia e de policiamento sanitário.

A partir da forma como Nery expõe o quadro sanitário local, e coloca a responsabilidade da crise epidêmica de varíola na região ao "grande número de vapores profundos de outros Estados da República", percebemos uma questão levantada por SCHWEICKARDT (2009, p.20),

As doenças tropicais permitem pensar questões como a divulgação e circulação das ideias científicas, a aplicabilidade destas ideias em termos locais, a utilização de técnicas e tecnologias para o combate das doenças, a elaboração das políticas públicas, a relação entre os médicos locais e as comissões médico-científicas externas, as condições geográficas da região(...). As doenças tropicais e a Amazônia são duas categorias que

\footnotetext{
9 Foi um Oficial do Exército formado pela Escola Militar do Rio de Janeiro, foi governador do Amazonas entre 1904 e 1908, sendo sucessor de seu irmão de Silvério Nery, que foi governador entre 1900 e 1903. Beneficiado pelo crescimento econômico decorrente da exportação da borracha, foi responsável por importantes obras no Amazonas. (BERTARELLI, M. Disponível em < http://cpdoc.fgv.br/sites/default/ files/verbetes/primeirarepublica/NERY,\%20Antonio\%20Constantino.pdf > Acesso em: 20 maio 2020).
} 
possuem significados simbólicos diversos, e se relacionam na tentativa de compreensão do pensamento médico e das práticas científicas (...).

A partir dessa mensagem, percebemos que embora o debate sobre os microorganismos serem responsáveis pela origem de enfermidades tenha acontecido desde o final do século XIX, as mensagens lidas pelos governantes amazonenses à Assembleia Legislativa mostram que entre os dirigentes do estado havia continuidade da concepção miasmática como explicação para a manifestação de doenças na região. A mensagem do governador Raymundo Affonso de Carvalho ${ }^{10}$ (1908, p.19), mostra um exemplo de como as ações sanitárias adotadas no território amazonense não eram homogêneas,

O impaludismo, causa mais poderosa da mortandade nesta região em [o]utras épochas decresce, dia a dia, de um modo bem apreciável. Banido do centro da cidade, impera furtivamente nos subúrbios, que eram d'antes campo de suas devastações.

Tolhido pelos meios prophylaticos adequados ás suas manifestações, insurge-se em alguns pontos da além-zona suburbana onde predomina o descuido, se não a ignorância dos meios de que dispomos na actualidade para exterminal-o.

O distanciamento entre o que estava sendo discutido no cenário médico e a forma como as ações sanitárias empreendidas pelo governo do Amazonas em 1907 nos remete ao debate realizado pelo médico István van Deursen Varga (2007). Segundo ele, as políticas públicas de saúde foram desenvolvidas de forma secundária nos espaços de população rural, sendo praticadas como meios para outras atividades e não uma preocupação primária destinada a essas populações.

${ }^{10}$ Foi deputado estadual, em1901, tornou-se presidente da Assembleia Legislativa do Amazonas. Enquanto ocupava a presidência da Assembleia foi chamado, em 20 de novembro de 1907, a assumir o cargo de governador no lugar do coronel Antônio Constantino Nery, que se afastou para uma viagem à Europa. Governou o Amazonas até 23 de julho de 1908, quando chegou ao fim o mandato de Antônio Constantino Nery e tomou posse Antônio Clemente Ribeiro Bittencourt. Após deixar o governo, permaneceu ainda como presidente as Assembleia amazonense até 1909 (BERTARELLI, M. CARVALHO, Raimundo Afonso de. Disponível em: $<$ http://cpdoc.fgv.br/sites/default/files/verbetes/primeirarepublica/CARVALHO,\%20Raimundo\%20Afonso\%20de.pdf > Acesso em 20 maio 2020). 
No caso apresentado por governador Carvalho (1908), vemos que existe uma dicotomia "centro" e "subúrbio" para a forma como as ações sanitárias eram interiorizadas na região. Schweickardt (2009, p.32), contribui com esse debate ao também ressaltar que,

\begin{abstract}
Os sertões não recebiam o mesmo tratamento, pois eram deixados à sua própria dinâmica e vida. Por isso, o interior foi caracterizado como sendo outro Brasil, que era marcado por duas situações, uma sendo consequência da outra: a doença e a ausência do poder público. O caso do Amazonas exemplifica esta situação, pois a capital recebeu atenção das autoridades públicas, enquanto o interior somente era "socorrido" em períodos de epidemia.
\end{abstract}

O estado do Amazonas, como exposto no trecho acima, tal como os sertões era uma região que pouco ainda tinha sido explorada. Numa tentativa de ampliação do povoamento desse território de forma mais significativas, dois projetos foram muito importantes: a construção de linhas telegráficas que ligaram o estado ao Mato Grosso e a Estrada de Ferro Madeira-Mamoré, que perpassava os dois estados. Assim, progressivamente o Amazonas recebeu ainda mais atenção por parte do poder público, sobretudo no que tange as questões sanitárias.

Contribuindo para o debate entorno da contraposição entre os espaços "suburbanos" e "centrais" e, indo de encontro com a argumentação de Schweickardt (2009) está o trabalho dos professores Mueller e Oliveira (2003). No trabalho dos professores, é abordado sobre o modelo centro-periferia desenvolvido pelo sociólogo americano Edward Shils, que serve de base conceitual para a identificação de variáveis sobre o estudo da comunicação da ciência brasileira. Segundo o modelo do sociólogo,

(...) da zona central emanam influências que afetam, de várias maneiras, a existência das pessoas que vivem nessa sociedade, isto é, na própria zona central e nas zonas periféricas. O centro está onde se concentram o poder e a autoridade. O papel dos indivíduos e das instituições existentes na área de influência do centro não depende de sua situação geográfica, mas da sua relação com a zona central. Shils via a existência do centro como um fenômeno decorrente de um conjunto de valores e crenças que governam as sociedades e sugeriu que, na atitude das zonas periféricas em relação ao centro, havia algo parecido com a noção do sagrado. De um lado mais prático, descreveu o centro como uma estrutura social onde pessoas agem dentro de uma rede de instituições, gerando e propondo valores, crenças e práticas que são adotadas pelo resto da sociedade (MUELLER E OLIVEIRA, 2003, p.58-59). 
Nesse sentido, podemos estabelecer uma relação entre o relatório do governador Raymundo Carvalho, em 1908, e a noção exposta por Shils sobre a existência de uma influência do centro para com os subúrbios. No caso exposto pelo governador sobre o gerenciamento da crise sanitária no Amazonas, observamos que o centro descreve uma estrutura social que busca ser adotada pelo restante da sociedade amazonense.

O governador Carvalho (1908) aponta que nas regiões para além do centro, isto é, nos subúrbios, a lógica seguida foge ao esperado, devido ao descuido dos habitantes da região. Mas o que não fica claro em sua exposição é em que medida os serviços prestados aos espaços centrais influenciam, ou até mesmo executados, também nesses locais mais afastados do centro do Estado. A partir dessa dicotomia e da existência de dinâmicas próprias em diferentes localidades do Amazonas, julgamos mais prudente nos referirmos ao Estado como "os Amazonas", dada a diversidade de situações políticas e sobretudo, sanitárias enfrentadas por distintas regiões, mesmo que próximas de um mesmo plano geográfico.

A mensagem do governador Antônio Clemente Ribeiro Bittencourt ${ }^{11}$ (1909, p.31), é um exemplo das demandas que o Amazonas precisava para eliminar os focos de contaminação e diminuir a quantidade de casos de doenças endêmicas naquela região,

Se as condições financeiras do Estado e do Municipio permitissem, eu já teria extinguido, de accôrdo com o sr. Superintendente municipal, esses fócos miasmáticos, de onde, em grandes legiões, se levantam os mosquitos, que, segundo a Sciencia Média Moderna, são transmissores do impaludismo e da febre amarela.

\footnotetext{
${ }^{11}$ Eleito três vezes como deputado estadual do Amazonas pelo Partido Democrata, tornando-se oposição de ao partido em 1896. Vice-governador no governo de Antônio Constantino Nery. Em 1908 foi eleito governador do Amazonas, recebeu apoio do Partido Democrata e do governo do presidente da República Afonso Pena. Foi deposto por um golpe militar em 1912 (URBINATTTI, I. BITTENCOURT, Antônio Clemente Ribeiro. Disponível em: $<$ http://cpdoc.fgv.br/sites/default/files/verbetes/primeirarepublica/BITTENCOURT, $\% 20 \mathrm{Ant} \% \mathrm{C} 3 \%$ B4nio\%20Clemente\%20Ribeiro.pdf $>$ Acesso em: 20 maio 2020).
} 
Infelizmente, por ora, só podemos ir remediando o mal e não extinguil-o, conforme nosso desejo, devido ao estado de pobreza a que está reduzido o Thesouro Publico do Amazonas.

Como apontado pelo governador Bittencourt (1909), a problemática situação financeira do estado prejudicou a execução de medidas de saneamento ao estado. De acordo com Lídia Xavier (2006, p.200), o ano de 1909 também foi um ano de grande desafio para a continuidade da construção da EFMM,

(...) Em 1909, os médicos do Hospital da Candelária, todos norteamericanos, se declararam sem condições de combater as doenças regionais, por desconhecerem os tipos de males que afetavam os operários da Madeira-Mamoré.

Devido à grande quantidade de enfermos e óbitos ocorridos no local de construção da ferrovia Madeira-Mamoré, o empreiteiro do projeto, o norte-americano Percival Farquhar teve a iniciativa de convidar o médico Oswaldo Cruz para fazer uma análise e dar seu parecer sobre essa situação. A comissão do médico chegou a Porto Velho em 1910, acompanhado por seu médico particular, Dr. Belizário Pena. Após estudos sobre a região, foi concluído que as doenças regionais, como a malária e o beribéri, tinham tratamento, desde que houvesse melhoria nas condições de vida e de trabalho a que eram submetidos os operários da Madeira-Mamoré, que para ele eram os reais causadores dos problemas de saúde na localidade (XAVIER, 2006, p.201).

Embora não seja comentado na mensagem dos governadores do Amazonas em 1910 e 1911, Oswaldo Cruz esteve fazendo suas análises ao longo desses anos. Na mensagem de 1910, o governador apresenta um relatório completo escrito pelo médico Alfredo Augusto da Matta para expor com mais detalhes a situação vivida no estado, destacando a quantidade de óbitos pelo impaludismo na região e a necessária de medidas urgentes para solucionar as questões apresentadas, 
Tabela 1 - Número de óbitos por impaludismo entre os anos de 1897 e $1909^{12}$

\begin{tabular}{|c|c|}
\hline Ano & Óbitos \\
\hline 1897 & 512 \\
\hline 1898 & 1.074 \\
\hline 1899 & 710 \\
\hline 1900 & 1.495 \\
\hline 1901 & 614 \\
\hline 1902 & 776 \\
\hline 1903 & 766 \\
\hline 1904 & 914 \\
\hline 1905 & 525 \\
\hline 1906 & 411 \\
\hline 1907 & 732 \\
\hline 1908 & 476 \\
\hline 1909 & 477 \\
\hline
\end{tabular}

Além das informações presentes na tabela exposta acima, o médico Alfredo Augusto da Matta aponta afirma a ocorrência de dois casos de paludismo, “(...) o total geral acusa 477, sendo 341 do paludismo agudo e 136 de paludismo chronico. Assignalemos o registro lethal do paludismo em Manáos, desde 1897" (BITTENCOURT, 1910, p. 97-98).

A realidade mostrada na mensagem do governador Bittencourt (1910) aponta que as dificuldades sanitárias e o número de vítimas não se alteram em relação a do

12 As informações apresentadas na mensagem foram organizadas em tabela para facilitar a compreensão. (BITTENCOURT, 1910, p.97-98. Disponível em: http://ddsnext.crl.edu/titles/164?terms $=\& i t e m \_i d=2920 \# ? \mathrm{c}=4 \& \mathrm{~m}=120 \& \mathrm{~s}=0 \& \mathrm{cv}=0 \& \mathrm{r}=0 \& \mathrm{xywh}$ $=0 \% 2 \mathrm{C}-417 \% 2 \mathrm{C} 3967 \% 2 \mathrm{C} 2799>$ Acesso em: 16 maio 2020). 
ano anterior, mas ainda assim apresentam relativa melhora se comparado ao ano de início de construção da EFMM (1907), ou anos anteriores, como 1900.

Em 1911 o governador do Amazonas tratou apenas sobre a possibilidade de uma nova delimitação da divisa com o Pará. Mas foi possível ter informações desse ano na mensagem enviada no ano seguinte. Segundo Bittencourt (1912, p.75),

Attendi sempre e com a maior prestesa a todas as reclamações e pedidos das autoridades municipaes do interior no que diz respeito á saúde publica, autorizando a Directoria do Serviço Sanitario a remeter ambulâncias e desiganando profissionais. Quase todas essas comissões foram motivadas pelo aparecimento ou recrudescência do paludismo, excepção da de Itacoatiara.

Embora a mensagem de 1911 não traga nenhum dado a respeito das condições de saúde vividas pelo estado, é possível perceber a presença de Oswaldo Cruz e sua comissão como importante para o diagnóstico do quadro sanitário e epidemiológico local. Por mais que não devamos conceber sua ação como responsável por mudanças imediatas na situação vivida pelas regiões dos Amazonas. O parecer do médico, aliado a uma melhora nas condições orçamentárias permitiu que em 1912 o governador conseguisse atender todas as demandas das autoridades municipais do interior e fornecer assistência aos profissionais de saúde.

Em 1912 também houve a inauguração da Ferrovia Madeira-Mamoré. Possuindo $364 \mathrm{~km}$ de extensão, contornou os rios Madeira e Mamoré e conectou as cidades entre Guajará-Mirim e Porto Velho. Segundo Ferreira (2005), a célebre frase sem autoria "Cada dormente ${ }^{13}$ representa uma vida humana" utilizada para referir-se ao contingente de óbitos durante a construção da ferrovia não corresponde à realidade de sua história.

Após analisar os anos em que a ferrovia foi consolidada, o historiador faz um balanço entre o número de pessoas que trabalharam e aqueles que faleceram durante

13 Dormente ou travessas, são peças colocadas de forma transversal à linha férrea, sobre elas, os trilhos são fixados. No caso da EFMM, para cada $1 \mathrm{~km}$ de trilhos foram utilizados 1.500 dormentes (FERREIRA, 2005, p.300). 


\section{Espacialidades}

a execução do projeto. As informações compiladas pelo autor foram organizadas em tabela para facilitar a compreensão,

Tabela 2 - Número de contratados e total de óbitos durante os anos da construção

\begin{tabular}{|c|c|c|}
\hline Ano & Número de contratados & Total de óbitos por ano \\
\hline 1907 & 446 & 6 \\
\hline 1908 & 2.450 & 425 \\
\hline 1909 & 4.500 & 428 \\
\hline 1910 & 6.024 & 419 \\
\hline 1911 & 5.664 & 209 \\
\hline 1912 & 2.733 & 1.552 \\
\hline Total & 21.817 & \\
\hline
\end{tabular}

Fonte: FERREIRA, 2005, p. 301.

A partir da listagem desses dados, Ferreira (2005) frisa que eles se referem aos números divulgados pelo Hospital da Candelária, e que os óbitos expostos aconteceram ao longo da linha férrea, em Porto Velho e em Santo Antônio. E que corresponde apenas aos trabalhadores, não a todos que morreram no local, ou daqueles que eram trabalhadores, mas por algum motivo abandonaram o trabalho. A imprecisão dos dados não permite que tenhamos uma clara estatística sobre a quantidade de vidas impactadas pela construção da ferrovia.

Outra questão importante é a de que a estatística é finalizada em 1912, mas isso não significa que o impacto das doenças na região tenha chegado ao fim após a finalização da ferrovia. Segundo Ferreira (2005, p.302), “(...) naturalmente, continuaram a haver óbitos, mas em número reduzido à melhoria das condições sanitárias da região, e dos melhores recursos de profilaxia das doenças".

O mesmo foi mostrado nas mensagens dos governadores do Amazonas à Assembleia Legislativa. Embora a documentação não trace um paralelo de influência 


\section{Espacialidades}

entre a melhora sanitária na EFMM sobre a regiões dos Amazonas, a melhora do quadro econômico do estado propiciou um trabalho mais eficiente das ações sanitárias e uma melhora significativa na saúde coletiva local.

\section{Considerações finais}

Como dito no início deste texto, buscamos desenvolver reflexões sobre o impacto que as diferentes dinâmicas política tiveram sobre as ações sanitárias e a saúde no estado do Amazonas entre 1907 e 1912, anos também de construção da Estrada de Ferro Madeira-Mamoré. Ao longo deste trabalho, percebemos como os interiores do estado foram diferentemente afetados por essas dinâmicas.

O uso de "interiores" e "dos Amazonas" foi resultado da reflexão obtida com o texto de Albuquerque Júnior (2008), afinal, levando em consideração que a construção de uma "região" é palco de diversas disputas e do delineamento de fronteiras que não necessariamente correspondem a uma homogeneidade de ações e valores, não é possível reduzir as localidades mais extremas do Estado do Amazonas a um interior único, muito menos a uma realidade sanitária una.

A partir das mensagens dos governadores do Amazonas para a assembleia legislativa, não foi possível perceber se a presença das comissões sanitárias na construção da EFFM significou em uma mudança no quadro sanitário apresentado no estado do Amazonas. A melhora das condições sanitárias ocorrida na região é descrita como consequência à ascensão econômica vivida pelo estado durante o período analisado.

Devido à sua imensidão territorial e a disparidade na forma com que os serviços de saúde eram ofertados dentro do território, não podemos afirmar que as ações sanitárias foram eficazes nos "subúrbios" de forma semelhante ao "centro". A partir da mensagem do governador Antônio Clemente Ribeiro Bittencourt (1912), temos conhecimento de que após uma série de pedidos, naquele ano todas as 
solicitações das autoridades municipais dos interiores haviam sido atendidas e o serviço de atendimento em casos de impaludismos estavam sendo atendidos.

Pela construção da mensagem e o histórico sanitário exposto ao longo de 1907 e 1912, vemos que uma mudança no acesso de serviços aos interiores de forma eficaz foi anunciada em 1912. O fato desse movimento acontecer a partir de uma alteração econômica vai de encontro com um apontamento que Schweickardt (2009, p.32) problematiza no início de sua tese, “(...)os interesses sobre a região foram se alternando de acordo com as atividades socioeconômicas que ali se desenvolveram”. E tal como os interesses, o acesso aos meios para a melhora sanitária e de saúde parece ter seguido essa mesma linha de desenvolvimento na região que abarca o Estado do Amazonas durante as primeiras décadas do Brasil republicano.

\section{REFERÊNCIAS}

ALBUQUERQUE JÚNIOR, D. M. O objeto em fuga: algumas reflexões em torno do conceito de região. Fronteiras. Dourados, MS, vol. 10, n. 17, p. 55-67, jan./jun 2008.

BENCHIMOL, J. L.; SILVA, A. F. C. da. Ferrovias, doenças e medicina tropical no Brasil da Primeira República. História, Ciências, Saúde. Manguinhos, Rio de Janeiro, v.15, n.3, p.719-762, jul.-set 2008.

BERTARELLI, M. CARVALHO, Raimundo Afonso de. In: CPDOC - Centro de Pesquisa e Documentação de História Contemporânea do Brasil. FGV. Rio de Janeiro: CPDOC, s/d. Disponível em: <http://cpdoc.fgv.br/sites/default/files/verbetes/primeirarepublica/CARVALHO,\%20Raimundo\%20Afonso\%20de.pdf $>$ Acesso em 20 maio 2020.

NERY, Antônio Constantino. In: CPDOC - Centro de Pesquisa e Documentação de História Contemporânea do Brasil. FGV. Rio de Janeiro: CPDOC, s/d. Disponível em: < http://cpdoc.fgv.br/sites/default/files/verbetes/primeirarepublica/NERY,\%20Antonio\%20Constantino.pdf> Acesso em: 20 Maio 2020.

BITTENCOURT, A. C. R. Mensagem lida perante o Congresso do Amazonas na abertura da Terceira sessão ordinária da sexta legislatura pelo exm. Snr. C.el. Antonio Clemente Ribeiro Bittencourt, governador do Estado em 10 de julho de 1909. In: CRL Digital Delivery System (Center of Research Libraries). Manaus: Imprensa 
oficial, 1909 Disponível em: < http:/ /ddsnext.crl.edu/titles /164?terms =\&item_id=2957\#?c=4\&m=119\&s=0\&cv $=0 \& \mathrm{r}=0 \& x y w h=0 \% 2 \mathrm{C}-506 \% 2 \mathrm{C} 3647 \% 2 \mathrm{C} 2573>$ Acesso em: 16 maio 2020 .

Mensagem lida perante o Congresso dos representantes por ocasião da Abertura da primeira sessão ordinária da sétima legislatura em 10 de julho de 1910 pelo governador do Estado C.el. Antonio Clemente Ribeiro Bittencourt acompanhada dos relatórios dos chefes de repartições. In: CRL Digital Delivery System (Center of Research Libraries). Manaus: Imprensa oficial, 1910. Disponível em:

http:/ /ddsnext.crl.edu/titles / 164?terms =\&item_id=2920\#?c=4\&m =120\&s=0\&cv $=0 \& \mathrm{r}=0 \& \mathrm{xywh}=0 \% 2 \mathrm{C}-417 \% 2 \mathrm{C} 3967 \% 2 \mathrm{C} 2799>$ Acesso em: 16 maio 2020 .

Mensagem lida perante o Congresso do Amazonas na abertura da Terceira sessão ordinária da sétima legislatura pelo exm. Snr. C,el. Antonio Clemente Ribeiro Bittencourt governador do Estado em 10 de julho de 1912. In: CRL Digital Delivery System (Center of Research Libraries). Manaus: Imprensa oficial, 1912. Disponível em:

http:/ /ddsnext.crl.edu/titles $/ 164$ ?terms $=\& i t e m \_i d=2961 \# ? c=4 \& m=124 \& s=0 \& c v$ $=0 \& \mathrm{r}=0 \& x y w h=-134 \% 2 \mathrm{C}-328 \% 2 \mathrm{C} 4187 \% 2 \mathrm{C} 2954>$ Acesso em: 16 maio 2020 .

CARVAlHO, R. A. de. Mensagem lida perante o Congresso do Amazonas na abertura da Segunda sessão ordinária da sexta legislatura pelo C.el. Raymundo Affonso de Carvalho, Presidente do Congresso Legislativo no exercício de Governador do Estado em 10 de julho de 1908. In: CRL Digital Delivery System (Center of Research Libraries). Manaus: Imprensa oficial, 1908. Disponível em: < http:/ /ddsnext.crl.edu/titles $/ 164$ ?terms $=\& i t e m \_i d=2956 \# ? c=4 \& m=118 \& s=0 \& c v$ $=0 \& \mathrm{r}=0 \& \mathrm{xywh}=-267 \% 2 \mathrm{C}-129 \% 2 \mathrm{C} 3652 \% 2 \mathrm{C} 2576>$ Acesso em: 16 maio 2020.

CASER, A. T. O medo do Sertão: doenças e ocupação do território na comissão de linhas telegráficas estratégicas de Mato Grosso ao Amazonas (1907-1915), 2009. 137p. Dissertação (Mestrado) Fundação Oswaldo Cruz. Casa de Oswaldo Cruz, Rio de Janeiro, 2009.

MUELLER, S.; OLIVEIRA, H. Autonomia e dependência na produção da ciência: uma base conceitual para estudar relações na comunicação científica. Perspect. cienc. inf., Belo Horizonte, v. 8, n. 1, p.58-65, jan./jun. 2003

NERY, A. C. Mensagem lida perante o Congresso do Amazonas na abertura da Primeira sessão ordinária da sexta legislatura pelo governador do Estado Dr. Antonio Constantino Nery em 10 de julho de 1907. In: CRL Digital Delivery System (Center of Research Libraries) Manaus: Imprensa oficial, 1907. Disponível em: < http:/ /ddsnext.crl.edu/titles $/ 164$ ?terms $=$ \&item_id $=2954 \# ? \mathrm{c}=4 \& \mathrm{~m}=116 \& \mathrm{~s}=0 \& \mathrm{cv}$ $=0 \& \mathrm{r}=0 \& x y w h=-149 \% 2 \mathrm{C}-284 \% 2 \mathrm{C} 3625 \% 2 \mathrm{C} 2557>$ Acesso em 16 maio 2020. 
PEITER, P. C. Geografia da Saúde na Faixa de Fronteira Continental do Brasil na Passagem do Milênio, 2005. 334p. Tese (Doutorado) Universidade Federal do Rio de Janeiro. Rio de Janeiro, 2005.

SANTOS, L. A. de C. O pensamento sanitarista na Primeira República: Uma ideologia de construção da nacionalidade. Dados. Revista de Ciências Sociais, Rio de Janeiro, v.28, n.2, p.193-210, 1985.

SCHWEICKARDT, J. C. Ciência, nação e região: as doenças tropicais e o saneamento no Estado do Amazonas (1890-1930). 2009. 425p. Tese (Doutorado). Fundação Oswaldo Cruz. Casa de Oswaldo Cruz, Manaus 2009.

SUFRAMA - Superintendência da Zona Franca de Manaus. Amazônia Ocidental. Suframa Invest. Amazonas, AM: SUFRAMA, 2013. Disponível em: http://www.suframa.gov.br/invest/zona-franca-de-manaus-amazoniaocidental.cfm> Acesso em 13/05/2020.

URBINATTI, I. BITTENCOURT, Antônio Clemente Ribeiro. In: CPDOC - Centro de Pesquisa e Documentação de História Contemporânea do Brasil. FGV. Rio de Janeiro: CPDOC, s/d. Disponível em: < http://cpdoc.fgv.br/sites/default/files/verbetes/primeira-

republica/BITTENCOURT, $\% 20 \mathrm{Ant} \% \mathrm{C3} \% \mathrm{~B} 4$ nio $\% 20$ Clemente $\% 20$ Ribeiro.pdf> Acesso: 20 maio 2020.

UJVARI, S da C. A história e suas epidemias: a convivência do homem com os micróbios, $2^{\circ}$ ed, SENAC: São Paulo, 2003, 281p.

VARGA, I. Fronteiras da urbanidade sanitária: sobre o controle da malária. Saúde e Sociedade v.16, n.1, p.28-44, jan-abr 2007.

VITAL, A. V. Medicina tropical, tratamento e profilaxia contra a malária: controvérsias científicas no início do século XX. Revista Eletrônica Cadernos de História, vol.10, ano 5, n. ${ }^{\circ}$ 2, p.1-9, dez 2010.

XAVIER. L. Fronteira Oeste Brasileira: entre o contraste e a integração.2006. 242p. Tese (Doutorado). UNB, Brasília, 2006. 